This is the author's final, peer-reviewed manuscript as accepted for publication. The publisher-formatted version may be available through the publisher's web site or your institution's library.

\title{
Comparative gut transcriptome analysis reveals differences between virulent and avirulent Russian wheat aphids, Diuraphis noxia
}

Radhika Anathakrishnan, Deepak K. Sinha, Marimuthu Murugan, Kun Yan Zhu, MingShun Chen, Yu Cheng Zhu, C. Michael Smith

\section{How to cite this manuscript}

If you make reference to this version of the manuscript, use the following information:

Anathakrishnan, R., Sinha, D. K., Murugan, M., Zhu, K. Y., Chen, M. S., Zhu, Y. C., \& Smith, C. M. (2014). Comparative gut transcriptome analysis reveals differences between virulent and avirulent Russian wheat aphids, Diuraphis noxia. Retrieved from http://krex.ksu.edu

\section{Published Version Information}

Citation: Anathakrishnan, R., Sinha, D. K., Murugan, M., Zhu, K. Y., Chen, M. S., Zhu, Y. C., \& Smith, C. M. (2014). Comparative gut transcriptome analysis reveals differences between virulent and avirulent Russian wheat aphids, Diuraphis noxia. Arthropod-Plant Interactions, 8(2), 79-88.

Copyright: (C) Springer Science+Business Media Dordrecht 2014

Digital Object Identifier (DOI): doi:10.1007/s11829-014-9293-4

Publisher's Link: http://link.springer.com/article/10.1007\%2Fs11829-014-9293-4

This item was retrieved from the K-State Research Exchange (K-REx), the institutional repository of Kansas State University. K-REx is available at http://krex.ksu.edu 
Comparative gut transcriptome analysis reveals differences between virulent and avirulent Russian wheat aphids, Diuraphis noxia

Radhika Anathakrishnan e-mail: radhyka@gmail.com, No. 4, Visalakshi Street, Arumbakkam, Chennai 600106 India; Deepak K. Sinha e-mail: dksinha@k-state.edu, Department of Entomology, Kansas State University, Manhattan, KS 66506-4004 USA; Marimuthu Murugan e-mail: muruganmarimuthu1969@gmail.com, Department of Plant Molecular Biology and Biotechnology, Centre for Plant Molecular Biology, Tamil Nadu Agricultural University, Coimbatore 641003 India; Kun Yan Zhu e-mail: kzhu@ksu.edu, Department of Entomology, Kansas State University, Manhattan, KS 66506-4004 USA; Ming-shun Chen e-mail: mchen@ksu.edu, USDA/ARS and Department of Entomology, Kansas State University, Manhattan, KS 66506 USA, Yu Cheng Zhu e-mail: yc.zhu@ars.usda.gov, USDA-ARS-JWDSRC, 141 Experiment Station Road, Stoneville, MS 38776 USA, and C. Michael Smith e-mail: cmsmith@ksu.edu, Department of Entomology, Kansas State University, Manhattan, KS 66506-4004 USA

Running Title: Russian wheat aphid gut transcriptomes

Keywords: biotype, Diuraphis noxia, phloem feeder, plant resistance, Buchnera, transcriptome analysis

Type of article: Original research paper 
Corresponding Author: C. Michael Smith ( ) ) Department of Entomology, Kansas State University, Manhattan, KS 66506-4004 USA, phone: 785-532-4700, FAX: 785-5326232

e-mail: $\underline{\text { cmsmith@,ksu.edu }}$ 


\begin{abstract}
The Russian wheat aphid, Diuraphis noxia, is a destructive pest of cereal crops that exhibits virulence to $D$. noxia resistance genes in wheat. Therefore, it is important to identify $D$. noxia virulence factors. The insect gut, the primary site of defense to ingested toxins, is also a likely site of differential gene expression in virulent insects. Comparative analyses of gut transcriptomes from virulent and avirulent $D$. noxia can improve an understanding of aphid gut physiology and may reveal factors critical to compatible D. noxia-wheat interactions. A total of 4, 600 clones were sequenced from gut cDNA libraries prepared from avirulent (biotype 1) and virulent (biotype 2) D. noxia feeding on biotype 1-resistant wheat. A majority of the sequences (66\% in biotype $1,64 \%$ in biotype 2 ) matched those from the NR database. BLASTX analysis of sequences with the highest E-values revealed that $59 \%$ of the biotype 1 sequences matched those of the pea aphid, Acyrthosiphon pisum. However, only $17 \%$ of the biotype 2 sequences were similar to those of $A$. pisum. RT-qPCR expression analyses confirmed that the biotype 2 gut transcriptome differs significantly from that of biotype 1. A transcript coding the tRNA-Leu gene was significantly up-regulated in the biotype 2 transcriptome, strongly suggesting that leucine metabolism is a critical factor in biotype 2 survival. Many more transcripts encoding protease inhibitors occurred in the avirulent biotype 1 gut than in the gut of virulent biotype 2 . However, more protease transcripts occurred in the biotype 2 gut than in the biotype 1 gut, suggesting that the avirulent biotype produces protease inhibitors in response to plant proteases. The virulent biotype 2 produces trypsin-like and chymotrypsin-like serine protease counter-defenses to overcome biotype 1-resistant plants.
\end{abstract}




\section{Introduction}

Common bread wheat is a vital cereal food crop, serving as a major source of carbohydrate and protein for the world population. However, wheat is challenged by many pathogens and arthropods that significantly reduce yields (Berzonsky, 2003). The Russian wheat aphid, Diuraphis noxia, (Kurdjumov) is one of the most destructive global arthropod pests of wheat (Webster and Kenkel, 1999). D. noxia foliar feeding causes leaf vein chlorosis, failure of leaves to unfurl (forming a tube-like structure), destruction of chlorophyll, and resultant incomplete head emergence and yield loss (Marasas, 1999). D. noxia, first described by Grossheim (1914) as a pest of barley in Russia, has since dispersed into Africa, Asia, Europe, the Middle East, and most recently into North and South America (Walters et al. 1980; Starý, 1996; Souza, 1998; Clua et al. 2004; Zhang et al., 2001). In response to $D$. noxia-related yield losses, numerous $D$. noxia-resistant varieties of barley and wheat have been developed and deployed, primarily in North America and South Africa (Mornhinweg et al. 2006; Tolmay et al. 2006). Nevertheless, virulent genotypes of $D$. noxia referred to as biotypes now exist that are unaffected by otherwise resistant plants (Basky, 2003; Haley et al. 2004; Smith et al. 2004; Dolatti et al. 2005; Burd et al. 2006; Malinga et al. 2007; Tolmay et al. 2006). Therefore, there is an urgent need to understand the relationship between molecular mechanisms of wheat defenses against $D$. noxia and corresponding $D$. noxia counter defenses.

In aphids and other insects, the digestive system constitutes an important site of counter-defense against a wide range of plant defense molecules, both constitutive and induced, in response to insect herbivory. The ingestion and digestion of plant nutrients by aphids involves a series of molecular, biochemical and physiological reactions (Terra and 
Ferriera, 2005, Tagu et al. 2005) aimed at neutralizing host plant defense allelochemicals or manipulating plant defense machinery. Various transcriptome studies have characterized aphid gut genes involved in detoxification and digestion (Hunter et al. 2003, Tagu et al. 2004, Sabater-Munoz et al. 2006, Ramsey et al. 2007) as well as other phytophagous insects (Goates et al. 2008, Khajuria et al. 2009, Pedra et al. 2003, Chi et al. 2009, Simpson et al. 2007, Sinha et al. 2011). However, little is known about D. noxia gut proteins, and a need exists to understand the gut transcriptomes of $D$. noxia biotypes. The identification of $D$. noxia detoxification and digestive enzymes may contribute to an improved understanding of biotype differentiation, as well as the identification of putative $D$. noxia factor(s) that may be important for overcoming host resistance.

Other than differential plant foliar damage (Burd et al. 2006, Haley et al. 2004) and related differences in the feeding behavior, growth and survival of different $D$. noxia biotypes (Khan et al. 2009, Lazzari et al. 2009), little is known about the ecological and genetic factors underlying the development of $D$. noxia biotypes. Therefore, we investigated alterations in the $D$. noxia gut transcriptome that may identify genes involved in $D$. noxia-wheat interactions. $D$. noxia biotypes 1 and 2, first identified in the United States (Burd et al. 2006), were used for the study. Biotype 2 (RWA2) can feed and survive successfully on plants containing the Dn4 resistance gene, while biotype 1 (RWA1) is avirulent to Dn4 plants. Our hypothesis was that RWA2 exhibits a gut transcriptome that is significantly different from that of RWA1 after feeding on RWA1 resistant-wheat plants. We characterized the differential expression of selected genes in the guts of RWA1 and RWA2, each fed on RWA2-susceptible and RWA1-resistant wheat plants containing the Dn4 resistance gene. Selective screening of 4,600 clones 
identified unique genes expressed in both biotypes, and expression of genes of interest was validated using quantitative real time-PCR (RT-qPCR). These results provided valuable insights into the qualitative and quantitative differences in the gut transcriptomes of virulent and avirulent $D$. noxia biotypes.

\section{Materials and methods}

Plant infestation and aphid gut dissections

Approximately 100 D. noxia adults each of RWA1 and RWA2 from laboratory colonies of each, maintained separately on susceptible 'Jagger' wheat, were starved for $12 \mathrm{~h}$ and fed on Dn4 wheat plants in a fine screen mesh cage in the greenhouse. At 24, 48, 72, and $96 \mathrm{~h}$ post-infestation, approximately 100 adults of each biotype were collected from Dn4 plants. The gut tissues of all aphids were dissected on the day of collection for library preparation. Both 'Jagger' and Dn4 plants were grown in the greenhouse in $16.5-\mathrm{cm}$ diam. plastic pots containing Pro-Mix-Bx potting mix (Premier ProMix, Lansing, MI, USA). Environmental conditions were $24: 20^{\circ} \mathrm{C}$ day/night with a photoperiod of $14: 10$ $[\mathrm{L}: \mathrm{D}] \mathrm{h})$.

Aphids were individually placed in DEPC treated water in a deep-welled glass slide, viewed at $80 \mathrm{X}$ magnification using a Nikon SMZ1500 microscope, and the intact gut was dissected using a biologie tip and Dumont forceps. Guts were immediately transferred to $200 \mu \mathrm{l}$ of Tri-Reagent ${ }^{\circledR}$ solution (Ambion Inc, Foster City, CA, USA) and stored in $-80^{\circ} \mathrm{C}$. Dissected guts of each biotype were pooled, and from these samples, 
approximately 400 guts from each biotype were accumulated for RNA isolation. For RTqPCR assays, 50 guts from each biotype, collected at 24, 48, 72 and $96 \mathrm{~h}$ post-infestation were placed in RLT buffer from a RNeasy Microkit (Qiagen GmbH, Hilden, Germany).

D. noxia gut RNA isolation and cDNA library construction

RNA isolation was performed using Tri-Reagent ${ }^{\circledR}$ solution (Ambion Inc, Foster City, CA, USA), according to the manufacturer's protocol. After centrifugation, the supernatant was transferred to a new tube and RNA was precipitated by adding an equal volume of cold isopropanol. A RNA pellet was collected by centrifugation, washed with $80 \%$ ethanol, dissolved in $50 \mu 1 \mathrm{DEPC}$ water, and incubated at $55^{\circ} \mathrm{C}$ in a water bath for 10 min. RNA quality was determined using a NanoDrop 2000 UV-Vis spectrophotometer (Thermo Scientific, Wilmington, DE, USA) and $2 \mu 1$ was electrophoresed on a formaldehyde-agarose gel to check the integrity of RNA bands.

RNA samples from each biotype were used to construct one cDNA library for each biotype, using the Creator Smart Clontech kit (Palo Alto, CA). In order to decrease the number of clones with small insert sizes, those with bands $\geq 250 \mathrm{bp}$ of bands were size-selected and eluted from a 1.5\% agarose gel for cloning. Resulting clones were Sanger sequenced (both 5' and 3' ends) in 2007 at the Genomics and Bioinformatics Research Unit, USDA/ARS Jamie Whitten Delta States Research Center in Stoneville, MS (RWA2), and at AGCT Inc., Wheeling, IL (RWA1). RNA isolation for RT-qPCR was performed using the RNeasy Micro kit (Qiagen GmbH, Hilden, Germany) according 
to the manufacturer's protocol. On-column DNAse I digestion was performed to remove DNA contamination before proceeding to cDNA synthesis and RT-qPCR.

Sequencing, transcript assembly and data analysis

Approximately 2, 400 clones for RWA1 library and 2, 200 clones for the RWA2 library were sequenced at the facilities mentioned above. After Phred analysis (Phred score $>30$ ), removal of mononucleotide regions and vector trimming was performed. Clusters were developed using the CAP3 aligner (http://pbil.univ-lyon1.fr/cap3.php). A cluster was either a contig containing several ESTs (high quality consensus sequence) or a singleton containing only one EST. After assembly, sequences in each library were analyzed using BLASTX and BLASTN public domain software at NCBI (http://greengene.uml.edu/programs/NCBI_Blast.html). Gene Ontology (GO) terms were assigned using the BLAST2GO tool (http://www.blast2go.com/b2ghome) and KEGG analysis (http://www.genome.jp/kaas-bin/) was performed to map the genes in different metabolic pathways. Secretory signal sequences were predicted using Signal P server (http://www.cbs.dtu.dk/services/SignalP/). Identification of microsatellite repeats in the sequences was performed using the SSRIT tools (http://www.gramene.org/db/markers/ssrtool). E-value cut off for sequence inclusion was $\leq 10^{-3}$.

Comparative analysis using count library analysis software 
The number of transcripts in each library contributing to a particular contig was derived using the custom program, Count Libraries (JMC Ribeiro, NIH). Transcript abundance in gut tissues of RWA1 and RWA2 was compared using Chi-square analysis, to identify quantitative differences in numbers of specific gut sequences (Ribeiro et al. 2006).

RT-qPCR and Statistical analysis

RNA isolated from the midguts of RWA1 and RWA2 feeding on Dn4 plants was used for RT-qPCR. An equal quantity (100ng) of total RNA was transcribed to first strand using the SuperScript III First-Strand synthesis super mix for RT-qPCR (Life Technologies, Grand Island, NY, USA) according to the manufacturer's protocol. RT-qPCR primers were designed using the Beacon Designer Probe/Primer design software (Biorad, Hercules, CA, USA) (Table 1). RT-qPCR was performed on a CFX 96 Touch Real Time PCR detection system (Biorad, Hercules, CA, USA). Each primer pair was amplified and checked for dimers in a $2 \%$ agarose gel. Further, serial dilutions of the cDNAs were prepared and RT-qPCR performed with each primer pair to generate a standard curve and to estimate PCR efficiency. Each $10 \mu 1$ of PCR mix contained cDNA (1 $1 \mu 1$ of the first strand generated), $1 \mathrm{X}$ iTaq Universal SYBR green supermix and $0.5 \mathrm{mM}$ of forward and reverse primers. The RT-qPCR cycling conditions were $95^{\circ} \mathrm{C}$ for 2 min followed by 40 cycles of $95^{\circ} \mathrm{C}$ for $30 \mathrm{~s}, 50^{\circ} \mathrm{C}$ or $53^{\circ} \mathrm{C}$ for $30 \mathrm{~s}$ and $72^{\circ} \mathrm{C}$ for $30 \mathrm{~s}$. Fluorescence was detected at annealing temperature in all reactions. Results were analyzed using the $2^{-\Delta \Delta \mathrm{Ct}}$ method, a function of the CFX Manager Software v3.0, using the relative expression value of RWA1 midgut genes as the calibrator. Actin, constitutively expressed in A. pisum (Mao 
and Zeng 2012) was used as the internal control for all RT-qPCR assays. Melt curve analysis was performed to identify primer dimers or contamination in PCR reactions. Two biological replicates and three technical replicates were included for the entire study. Results were analyzed for statistical significance using the CFX Manager Software v3.0 and presented as mean $\pm \mathrm{SD} \log _{2}$ relative expression.

\section{Results}

Sequence Analysis

The RWA1 gut library provided 2,400 clones and 1,565 trimmed sequences that produced 202 contigs and 685 singletons with an average length of $650 \mathrm{bp}$. The RWA2 gut library included 2,200 clones and 1,887 valid sequences that produced 288 contigs and 479 singletons with an average sequence length of $700 \mathrm{bp}$. All of these sequences have been deposited in NCBI dbEST database, bearing the library accession numbers LIBEST_028253. The majority of sequences (65.9\% from RWA1, 64.4\% from RWA2) matched known sequences in the NR database from arthropods, plants, parasites/fungi/ bacteria or other organisms. Fewer sequences (34.1\% from RWA1, 35.6\% from RWA2) were unknown with no hits in the EST database or showed similarity to hypothetical proteins. BLASTX analysis (E-value $\leq 10^{-3}$ ) indicated that $58.9 \%$ of RWA1 gut library sequences were similar to those in the A. pisum genome, and that surprisingly, only $17 \%$ of RWA2 gut library sequences were similar to A. pisum (Fig. 1). However, the RWA2 gut library showed similarity with genes from a more diverse group of species. 
Interestingly, $>10 \%$ of the RWA2 contigs (37) showed homology to those in Buchnera aphidocola, whereas only 3 RWA1 gut library contigs were similar to B. aphidocola (Fig. 1). The 10 species with greatest similarity to both RWA gut libraries are also shown in Fig. 1.

All sequences in both libraries homologous to known sequences were assigned GO terms for biological processes, molecular function or cellular components (Table S1 and Table S2). The top $20 \mathrm{GO}$ terms by molecular function were for increased peptidase and hydrolase activity and relatively decreased binding activity in the RWA2 gut, compared to the RWA1 gut (Fig. 2). Among all annotated sequences, $33.7 \%$ of the RWA1 gut library transcripts and $17.4 \%$ of the RWA2 gut library transcripts were mapped to various metabolic pathways (Table S3; Fig. 3). Genes from oxidative phosphorylation, protein export, proteasome and ribosome pathways were abundantly present in the RWA2 gut library when compared to the RWA1 gut library.

Numerous groups of genes related to food digestion, cuticle formation, detoxification, and other biological processes were identified in the two gut libraries. These included transcripts coding for trypsin- and chymotrypsin-like serine proteases, cathepsins, lipases, chitin synthase, cuticular proteins, ribosomal proteins and carboxypeptidases, as well as glutathione s-transferases, kinases, hydrolases, cytochrome P450 monooxygenases, and zinc finger proteins. There was a trend for greater numbers of proteases (11 contigs and 16 singlets) in the RWA2 gut library, compared to only 3 contigs and 2 singlets in the RWA1 gut library (Table 2).

Of 307 contigs and singlets in both libraries coding for proteins containing a secretory signal peptide, nearly twice as many (65) occurred in the RWA2 gut than in the 
RWA1 gut (39) (Table S4). All contigs were screened for the presence of hexa-, penta-, tetra-, tri- and di- nucleotide repeats, and 113 simple sequence repeat sequences (SSRs) possessing five or more repeats were identified. The majority was dinucleotide (58.6\%) or trinucleotide (39\%) repeats (Table S5).

Count Library Analysis

Chi-square analysis indicated that 64 contigs differed significantly between the two biotypes in the numbers of sequences present (Table S6). Sequences occurring in significantly greater numbers in RWA2 included chitin synthase, trypsin- and chymotrypsin-like serine proteases and precursors, cytochrome $\mathrm{C}$ oxidase subunits II and III, B. aphidicola proteins from A. pisum, ribosomal proteins and a nitrile-specific protein. Sequences occurring in significantly greater numbers in RWA1 included, but were not limited to a RR1 cuticle protein 2, a cytochrome oxidase subunit I, a heat shock protein 70, a GST-like protein, and ribosomal proteins L9, S3e, S24e. Additionally, 34 sequences matching B. aphidicola transcripts from A. pisum or S. graminum occurred uniquely in the RWA2 gut library and one B. aphidicola sequence matching the 50S ribosomal protein L21 from S. graminum was unique to the RWA1 gut library.

RT-qPCR and Statistical Analysis

Fourteen genes were selected for RT-qPCR analysis, based on differences between biotypes in the count analysis and their reported involvement in insect-plant interactions. 
Multiple bands were observed in the PCR amplification products of seven of the genes, and the remaining seven genes were standardized for RT-qPCR assay using SYBR green chemistry. PCR-primer efficiencies for the seven genes selected were within generally acceptable limits, and ranged from $93.1 \%$ to $113.8 \%$. The square of the coefficient of regressions $\left(R^{2}\right)$ was $\geq 0.99$. All expression values were normalized to the expression of the respective genes in RWA1 (Table 1). The expression of the kazal type proteinase inhibitor, cathepsin B, carboxypeptidase and glutathione $S$-transferase genes was significantly down-regulated $(\mathrm{p}<0.01)$ in the RWA2 gut transcriptome compared to the RWA1 transcriptome (Fig. 4). Conversely, the transcript coding for tRNA-Leu was significantly up-regulated $(\mathrm{p}<0.01)$ in the RWA2 gut transcriptome. There was no significant change in the expression levels of the serpin 4 or the single domain major allergen 2 transcripts at $p<0.01$, but at $p<0.05$, these genes were significantly more down-regulated in the RWA2 gut transcriptome than in the RWA1 transcriptome (Fig. 4).

\section{Discussion}

The insect gut is the primary site for food digestion, metabolism, and detoxification (Zhang et al. 2010); developmental regulation (Bajgar et al. 2013); and harbors beneficial microbes (Kikuchi et al. 2012). The gut transcriptomes of both hematophagous and phytophagous insects have been investigated extensively (Morris et al. 2009, Wang et al. 2011, Zhang et al. 2010, Boissière et al. 2012) but very few comparative studies of phytophagous insects have investigated global gut transcriptome changes among different biotypes. Thus, the results of our experiments take on additional relevance, since they 
represent the gut transcriptomic response of avirulent and virulent $D$. noxia biotypes feeding on a host plants containing a $D$. noxia resistance gene.

The current study is based on an assumption of similarity in sequence distribution of transcripts in each of two biotype libraries and it may be possible that the sequence distribution of some contigs/singlets is asymmetrically represented. However, this is likely not the case for our dataset, because the classes of genes were similarly represented in each library, and BLAST2GO analysis revealed a similar representation of genes from different GO terms and sub-categories. In addition, RT-qPCR results of a selected list of genes also provided similar patterns of up- and down-regulation in both the qPCR and count analysis experiments and these results were statistically significant. Finally, the percentage of annotated sequences was very similar for both libraries. Nevertheless, results are discussed in the context of percent representation of sequences to further nullify any bias.

The annotation of approximately $65 \%$ of the genes in the gut transcriptomes of each biotype was possible because of the presence of several sequenced insect genomes. However, we found it surprising to note the presence of greater sequence diversity in the RWA2 gut library, which shared maximum homology with that of several insect species. This result suggests that RWA2 gut transcriptome diversity may be related to the increased survival of RWA2 known to occur on RWA1-resistant wheat plants containing the Dn4 resistance gene (Haley et al. 2004; Weiland et al. 2008; Lazzari et al. 2009). Such a relationship occurs in Lepidoptera (Vandewoestijne et al. 2008) where lower genetic diversity decreases individual fitness. 
Another striking difference in the gut transcriptomes of the two biotypes is a large subset of B. aphidicola genes identified in RWA2. Approximately $20 \%$ of all insects live symbiotically with bacteria (Buchner, 1965) and symbiotic relationships are one key to the evolutionary success of insects (Moran and Baumamm, 2000). Successful aphid phloem feeding occurs because B. aphidicola endosymbionts synthesize essential amino acids and supplement nutrients present at low concentrations in phloem sap (Douglas, 2003; Wilkinson et al. 2000; Goggin 2007). The increased numbers of Buchnera transcripts in the RWA2 gut (Fig. 1) may be the result of either an over-expression of the respective genes or increased numbers of Buchnera cells. Both scenarios suggest Buchnera to play a crucial role in D. noxia - wheat interactions. The RT-qPCR results demonstrating significant over-expression of tRNA-Leu in the RWA2 gut transcriptome (Fig. 4) also point to the possibility that Buchnera functions in D. noxia biotypes and represents a novel finding. These results are substantiated by those of Swanevelder et al. (2010) who identified B. aphidicola plasmid leucine sequence differences in D. noxia biotypes in South Africa. We hypothesize that leucine metabolism is a key factor in RWA2 overcoming the resistance from Dn4 in incompatible interactions with RWA1. Proteases and protease inhibitors occur in insects feeding on both resistant-and susceptible host plants (Boigegrain et al. 2000; Hunter et al. 2003; Ramsey et al. 2007; Saadati and Bandani, 2011) and our results identified many such compounds in the $D$. noxia gut transcriptome. However, fewer proteases were detected in the RWA1 gut library than the RWA2 gut library, and fewer protease inhibitors also were detected in the RWA2 gut than in the RWA1 gut. Taken together, these results suggest that RWA1 is challenged by host plant proteases, and in response produces protease inhibitors. 
However, RWA2 is well adapted to survive defenses controlled by $\mathrm{Dn} 4$ and other $\mathrm{Dn}$ genes, and it is possible that the many trypsin-like- and chymotrypsin-like serine proteases in the RWA2 gut represent possible virulence "counter-defenses" that allow RWA2 to overcome RWA1-resistant wheat plants.

The study identified many $D$. noxia gut genes, including glutathione s-transferases and carboxypeptidases, involved in insect digestion and detoxification in insects (ffrench Constant et al. 2000; Gerardo et al. 2010). Glutathione s-transferases are known to detoxify reactive oxygen species related to plant stress in many arthropods (Ramsey et al. 2010) whereas carboxypeptidases are basically involved in insect digestion (Bown and Gatehouse, 2004). Increased numbers of glutathione s-transferases and carboxypeptidases in the RWA1 gut library, and their over-expression in RWA1 and corresponding downregulation in RWA2 support our hypothesis that the RWA2 gut transcriptome is significantly different from that of RWA1 after feeding on RWA1 resistant-wheat plants. The down-regulation of gluathione s-transferase in RWA2 strongly suggests that this biotype encounters a much less challenging environment while feeding on Dn4 plants than does RWA1. Nishikori et al. (2009) demonstrated the involvement of an A. pisum carboxypeptidase in Buchnera degradation, and for this reason, we hypothesize that the observed over-expression of carboxypeptidases in RWA1 may lead to Buchnera degradation and a resulting deficiency of essential amino acids vital for RWA1 survival. Nevertheless, additional in-depth experiments will be required to quantify B. aphidicola in RWA1 and in RWA2 after feeding on plants containing different $D$. noxia resistance genes. 
This study provides an initial step in the process of understanding the relationship between responses of $D$. noxia biotypes to wheat genotypes differing in biotype reaction. Specifically, the results of several experiments revealed significant differences in the gut transcriptomes of virulent- and avirulent biotypes. These transcriptomes provide the first experimental access to $D$. noxia gut-specific genes and serve as the basis for additional in-depth molecular and genomic analyses. Our results suggest that RWA2 is well adapted to counter the challenge posed by the wheat Dn4 RWA1 resistance gene, and that enhanced leucine metabolism is a critical factor in the success of RWA2. In summary, RWA2 has evolved a large set of gut enzymes, such as proteases, that act in favor of the biotype by either neutralizing the effect of a $\mathrm{Dn} 4$ plant $\mathrm{R}$ gene product or by adapting to the unfavorable environment of a Dn4 plant by production of amino acids. RWA1 responds to Dn4 defenses with a unique set of gut enzymes but these are ineffective, resulting in greatly reduced RWA1 fecundity and death.

D. noxia gut secretory proteins and simple sequence repeats identified in the data will also be useful tools for biologists to study plant-aphid interactions. Genes putatively identified in the $D$. noxia gut transcriptome are critical to aphid physiology and development and may also prove useful in non-chemical, gene-based aphid management strategies (Hunter et al. 2003). Future studies using RNAi technology to decipher amino acid metabolism in virulent and avirulent $D$. noxia will confirm the role(s) of amino acids in aphid-wheat interactions. Conversely, next generation sequencing technology studies of aphids feeding on wheat varieties containing different $\mathrm{Dn}$ genes can provide greater knowledge about plant molecular mechanisms functioning in $D$. noxia resistance. 
Acknowledgments We thank Drs. Marcelo Ortigao for critical reviews of drafts of the manuscript. This research was supported by grants to CMS from the Kansas Wheat Commission, the Kansas Crop Improvement Association, and the Kansas Agricultural Experiment Station. This is contribution No. 13-356-J of the Kansas Agricultural Experiment Station. This research was performed in the Gene Expression Facility at Kansas State University, which is supported through the National Science Foundation grant, DBI 0421427. 


\section{References Cited}

Bajgar, A., Jindra, M., Doleze, D. 2012. Autonomous regulation of the insect gut by circadian genes acting downstream of juvenile hormone signaling. Proceedings of the National Academy of Sciences of the United States of America, doi:10.1073/pnas.1217060110.

Basky, Z. 2003. Biotypic and pest status differences between Hungarian and South African populations of Russian wheat aphid, Diuraphis noxia (Kurdjumov) (Homoptera: Aphididae). Pest Management Science. 59:1152-1158.

Berzonsky, W.A., Ding, H., Haley, S.D., Lamb, R.J., McKenzie, R.I.H., Ohm, H.W., Patterson, F.L., Peairs, F.B., Porter, D.R., Ratcliffe, R.H., Shanower, T.G. 2003. Breeding wheat for resistance to insects. Plant Breeding Reviews. 22:221-296.

Boigegrain, R-A., Pugnière, M., Paroutaud, P., Castrod, B., Brehélin, M. 2000. Low molecular weight serine protease inhibitors from insects are proteins with highly conserved sequences. Insect Biochemistry and Molecular Biology. 30:145-152.

Boissière, A., Tchioffo, M.T., Bachar, D., Abate, L., Marie, A., Nsango, S.E., Shahbazkia, H.R., Awono-Ambene, P.H., Levashina, E.A., Christen, R., et al.,2012. Midgut microbiota of the malaria mosquito vector Anopheles gambiae and interactions with Plasmodium falciparum infection. PLoS Pathogens. 8: e1002742. 
Bown, D.P., Gatehouse, J.A. 2004. Characterization of digestive carboxypeptidase from the insect pest corn earworm (Helicoverpa armigera) with novel specificity towards Cterminal glutamate residues. European Journal of Biochemistry.10:2000-2011.

Buchner, P. 1965. Endosymbiosis of Animals with Plant Microorganisms. Interscience Publishers, New York.

Burd, J.D., Porter, D.R., Puterka, G.J., Haley, S.D., Peairs, F.B. 2006. Biotypic variation among North American Russian wheat aphid populations. Journal of Economic Entomology. 99:1862-1866.

Chi, Y.H., Salzman, R.A., Balfe, S., Ahn, J.E., Sun, W., Moon, J., Yun, D.J., Lee, S.Y., Higgins, T.J.V., Pittendrigh, B., Murdock, L.L., Zhu-Salzman, K. 2009. Cowpea bruchid midgut transcriptome response to a soybean cystatin-costs and benefits of counterdefence. Insect Molecular Biology. 18:97-110.

Clua, A.A., Castro, A.M., Ramos, S., Chidichimo, H., Dixon, A.F.G. 2004. The biological characteristics and distribution of Schizaphis graminum and Diuraphis noxia in Argentina and Chile. European Journal of Entomology. 101:193-198.

Dolatti, L., Ghareyazie, B., Moharramipour, S., Noori-Daloii, M.R. 2005. Evidence for regional diversity and host adaptation in Iranian populations of the Russian wheat aphid. Entomologia Experimentalis et Applicata. 114:171-180. 
Douglas, A.E. 2003. Nutritional physiology of aphids. Advances in Insect Physiology. $31: 73-140$.

ffrench-Constant, R.H., Anthony, N., Aronstein, K., Rocheleau, T., Stilwell, G. 2000. Cyclodiene insecticide resistance: from molecular to population genetics. Annual Review of Entomology. 45:449-466.

Gerardo NM, Altincicek B, Anselme C, Atamian H, Barribeau SM, de Vos M, Duncan EJ, Evans JD, Gabaldón T, Ghanim M, et al. 2010. Immunity and other defenses in pea aphids, Acyrthosiphon pisum. Genome Biology. 11:R21.

Goates, B.S., Sumerford, D.V., Hellmich, R.L., Lewis, L.C. 2008. Mining an Ostrinia nubilalis midgut expressed sequence tag (EST) library for candidate genes and single nucleotide polymophisms (SNPs). Insect Molecular Biology. 17:607-620.

Goggin, F.L. 2007. Plant-aphid interactions: molecular and ecological perspectives. Current Opinion in Plant Biology 10:399-408.

Grossheim, N.A. 1914. The barley aphid, Brachycolus noxius Mordvilko, in: Memoirs of the National History Museum of the Zemstvo of the Government of Taurida, Sinferopol. $3: 35-78$. 
Haley, S.D., Peairs, F.B., Walker, C.B., Rudolph, J.B., Randolph, T.L. 2004. Occurrence of new Russian wheat aphid biotype in Colorado. Crop Science 44:1589-1592.

Hunter, W.B., Dang, P.M., Bausher, M.G., Chaparro, J.X., McKendree, W., Shatters, R.G. Jr., McKenzie, C.L., Sinisterra, X.H. 2003. Aphid biology: Expressed genes from alate Toxoptera citricida, the brown citrus aphid. Journal of Insect Science. 3:23.

Khan, S. A., Murugan, M., Starkey, S., Smith, C. M. 2009. Inheritance and categories of resistance in wheat to Russian wheat aphid (Hemiptera: Ahididae) biotype 1 and biotype 2. Journal of Economic Entomology. 102: 1654-1662.

Khajuria, C., Zhu, Y-C., Chen, M.S., Buschman, L.L., Higgins, R.A., Yao, J., Muthukrishnan, S., Zhu, K.Y. 2009. Expressed sequence tags from the European cornborer (Ostrinia nubilalis) larval gut: identification of the genes potentially involved in Bacillus thuringiensis toxicity and resistance. BMC Genomics. 10:286.

Kikuchi, Y., Hayatsu, M., Hosokawa, T., Nagayama, A., Tago, K., Fukatsu, T. 2012. Symbiont-mediated insecticide resistance. Proceedings of the National Academy of Sciences of the United States of America. 109:8618-8622.

Lazzari, S., Starkey, S., Reese, J., Ray-Chandler, A., McCubrey, R., Smith, C. M. 2009. Feeding behavior of Russian wheat aphid (Hemiptera: Aphididae) biotype 2 in response 
to wheat exhibiting antibiosis and tolerance resistance. Journal of Economic Entomology. 102: 1291-1300.

Malinga, J.N., Kinuya, M.G., Kamau, A.W., Wanjama, J.K., Awalla, J.O., Pathak, R.S. 2007. Biotypic and genetic variation within tropical populations of Russian wheat aphid, Diuraphis noxia (Kurdjumov) (Homoptera: Aphididae) in Kenya. Journal of Entomology. 4:350-361.

Mao, J., Zeng, F. 2012. Feeding-based RNA interference of a gap gene is lethal to the pea aphid, Acyrthosiphon pisum. Plos ONE, 7, e48718. doi: 10.1371/journal.pone.0048718.

Marasas, C. 1999. Wheat management practices and adoption of the Russian wheat aphid integrated control programme in the study area. Socio-economic impact of the Russian wheat aphid integrated control programme. PhD thesis, University of Pretoria, Pretoria, South Africa.

Moran, N.A., Baumann, P. 2000. Bacterial endosymbionts in animals. Current Opinions in Microbiology. 3:270-275.

Mornhinweg, D.W., Brewer, M.J., Porter, D.R. 2006. Effect of Russian wheat aphid on yield and yield components of field grown susceptible and resistant spring barley. Crop Science. 49:36-42. 
Morris, K., Lorenzen, M.D., Hiromasa, Y., Tomich, J.M., Oppert, C., Elpidina, E.N., Vinokurov, K., Jurat-Fuentes, J.L., Fabrick, J., Oppert, B. 2009. Tribolium castaneum larval gut transcriptome and proteome: A resource for the study of the coleopteran gut. Journal of Proteome Research. 8:3889-3898.

Nishikori, K., Kubo, T., Morioka, M. 2009. Morph-dependent expression and subcellular localization of host serine carboxypeptidase in bacteriocytes of the pea aphid associated with degradation of the endosymbiotic bacterium Buchnera. Zoological Science. 6:415420.

Pedra, J.H.F., Brandt, A., Westerman, R., Lobo, N., Li, H.M., Romero-Severson, J., Murdock, L.L., Pittendrigh, B.R. 2003. Transcriptome analysis of the cowpea weevil bruchid: identification of putative proteinases and a-amylases associated with food breakdown. Insect Molecular Biology. 12:405-412.

Ramsey, J.S., Rider, D.S., Walsh, T., de Vos, M., Gordon, K., Ponnala, L., Roe, B.A., Jander, G. 2010. Comparative analysis of detoxification enzymes in Acrythrosiphon pisum and Myzus persicae. Insect Molecular Biology. 19:155-164.

Ramsey, J.S., Wilson, A.C., de Vos, M., Sun, Q., Tamborindeguy, C., Winfield, A., Malloch, G., Smith, D.M., Fenton, B., Gray, S.M., Jander, G. 2007. Genomic resources for Myzus persicae: EST sequencing. SNP identification, and microarray design. BMC Genomics. 8:423. 
Ribeiro, J. M., Alarcon-Chaidez, F., Francischetti, I. M., Mans, B. J., Mather, T. N., Valenzuela, J. G., Wikel, S. K. 2006. An annotated catalog of salivary gland transcripts from Ixodes scapularis ticks. Insect Biochemistry and Molecular Biology. 36:111-129.

Saadati, F., Bandani, A.R. 2011. Effects of serine protease inhibitors on growth and development and digestive serine proteinases of the Sunn pest, Eurygaster integriceps. Journal of Insect Science. 11:72.

Sabater-Munoz, B., Legeai, F., Rispe, C., Bonhomme, J., Dearden, P., Dossat, C., Duclert, A., Gauthier, J-P., Ducray, D.G., Hunter, W., et al. 2006. Large-scale gene discovery in the pea aphid Acyrthosiphon pisum (Hemiptera). Genome Biology. 7:21.

Simpson, R.M., Newcomb, R.D., Gatehouse, H.S., Crowhurst, R.N., Chagne, D., Gatehouse, L.N., Markwick, N.P., Beuning, L.L., Murray, C., Marshall, S.D., Yauk, YK., Nain, B.,Wang, Y-Y., Gleave, A.P., Christeller, J.T. 2007. Expressed sequence tags from the midgut of Epiphyas postvittana (Walker) (Lepidoptera: Tortricidae). Insect Molecular Biology. 16:675-690.

Sinha, D.K., Lakshmi, M., Anuradha, G., Rahman, S.J., Siddiq, E.A., Bentur, J.S., Nair, S. 2011. Serine proteases-like genes in the Asian rice gall midge show differential expression in compatible and incompatible interactions with rice. International Journal of Molecular Sciences. 12:2842-2852. 
Smith, C.M., Belay, T., Stauffer, C., Stary, P., Kubeckova, I., Starkey, S. 2004.

Identification of Russian wheat aphid (Homoptera: Aphididae) biotypes virulent to the Dn4 resistance gene. Journal of Economic Entomology. 97:1112-1117.

Souza, E.J. 1998. Host plant resistance to Russian wheat aphid (Homoptera: Aphididae) in wheat and barley, in: Quisenberry, S.S., Peairs, F.B. (Eds.) A Response Model for an Introduced Pest-The Russian Wheat Aphid. Thomas Say Publication in Entomology. Entomological Society of America, MD, pp. 122-47.

Starý, P. 1996. The expansive Russian Wheat Aphid, Diuraphis noxia (Mordw.) detected in the Czech Republic. Anzeiger Schädlingskunde / Journal of Pest Science. 69:19-20.

Swanevelder, Z.H., Surridge, A.K., Venter, E., Botha, A.M. 2010. Limited endosymbiont variation in Diuraphis noxia (Hemiptera: Aphididae) biotypes from the United States and South Africa. Journal of Economic Entomology. 103:887-97.

Tagu, D., Prunier-Leterme, N., Legeai, F., Gauthier, J.P., Duclerc, A., Sabater-Muñoz, B., Bonhomme, J., Simon, J.C. 2004. Annotated expressed sequence tags for studies of the regulation of reproductive modes in aphids. Insect Biochemistry and Molecular Biology. 8:809-822. 
Tagu, D., Sabater-Muñoz, B., Simon, J-C. 2005. Deciphering reproductive polyphenism in aphids. Invertebrate Reproductive Development. 48:71-80.

Terra, W.R., Ferreira, C. 2005. Biochemistry of digestion, in: Gilbert, L.I., Iatrou, K., Gill, S.S. (Eds.), Comprehensive Molecular Insect Science. Elsevier, Pergamon, Oxford, UK, pp. 171-224.

Tolmay, V., du Toit, F., Smith, C.M. 2006. Registration of Russian wheat aphid resistant near isogenic lines developed in South Africa. Crop Science. 46:478-480.

Vandewoestijne, S., Schtickzelle, N., Baguette, M. 2008. Positive correlation between genetic diversity and fitness in a large, well-connected metapopulation. BMC Biology. 6: 46.

Walters, M.C., Penn, F., Du Toit, F., Botha, T.C., Aalbersberg, K., Hewitt, P.H., Broodryk, S.W. 1980 The Russian wheat aphid. Farming South Africa Leaflet Service in Wheat G3: 1-6.

Wang, Y., Gilbreath, T.M. III, Kukutla, P., Yan, G., Xu, J. 2011. Dynamic gut microbiome across life history of the malaria mosquito Anopheles gambiae in Kenya. PLoS ONE. 6:e24767. 
Webster, J.A., Kenkel, P., 1999. Benefits of managing small-grain pests with plant resistance, in: Wiseman, B.R., Webster, J.A. (Eds.) Economic, Environmental and Social Benefits of Resistance in Field Crops. Thomas Say Publication in Entomology, Entomological Society of America, MD, pp. 87-114.

Weiland, A. A., Peairs, F. B., Randolph, J.B., Rudolph, J. B., Haley, S. D., Puterka, G. J. 2008.Biotypic diversity in Colorado Russian wheat aphid (Hemiptera: Aphididae) populations. Journal of Economic Entomology. 101: 569-574.

Wilkinson, T.L., Ishikawa, H. 2000. Injection of essential amino acids substitutes for bacterial supply in aposymbiotic pea aphids (Acyrthosiphon pisum). Entomologia Experimentalis et Applicata. 94:85-91.

Zhang, R., Liang, H., Ren, L., Zhang, G. 2001. Induced life cycle transition from holocycly to anholocycly of the Russian wheat aphid (Homoptera: Aphididae). Science in China Series C: Life Sciences. 44:1-4.

Zhang, S., Shukle, R., Mittapalli, O., Zhu, Y-C., Reese, J.C., Wang, H., Hua, B-Z., Chen, M.S. 2010. The gut transcriptome of a gall midge, Mayetiola destructor. Journal of Insect Physiology. 56:1198-1206. 
Table 1. RT-qPCR primers used to amplify genes from $D$. noxia gut libraries.

\begin{tabular}{|c|c|c|c|c|}
\hline Gene & Name & Primer Sequence (5’---3’) & $\begin{array}{l}\text { Tm } \\
\left({ }^{0} \mathrm{C}\right)\end{array}$ & $\begin{array}{l}\text { Amplicon } \\
\text { Size (bp) }\end{array}$ \\
\hline $\begin{array}{l}\text { Kazal type proteinase } \\
\text { inhibitor }\end{array}$ & $\begin{array}{l}511 \mathrm{~F} \\
511 \mathrm{R}\end{array}$ & $\begin{array}{l}\text { TGGTGTCAGTCAATGGCAGTCC } \\
\text { CGGGCTGGTGAAATCGTGGTC }\end{array}$ & 53 & 97 \\
\hline Serpin 4 & $\begin{array}{l}469 \mathrm{~F} \\
469 \mathrm{R}\end{array}$ & $\begin{array}{l}\text { TGTTGCCCGATGCTAAAGATGG } \\
\text { CAGCCCGTGTAAACATTGTAGGAC }\end{array}$ & 53 & 192 \\
\hline Cathepsin B & $\begin{array}{l}1475 \mathrm{~F} \\
1475 \mathrm{R}\end{array}$ & $\begin{array}{l}\text { GGAGGACATGCCGTGAAGTTG } \\
\text { CGTTTGTGCCTCGTCGAATTTG }\end{array}$ & 53 & 126 \\
\hline tRNA-Leu & $\begin{array}{l}57 \mathrm{~F} \\
57 \mathrm{R}\end{array}$ & $\begin{array}{l}\text { TTGCGACCTCGATGTTGGATTAAG } \\
\text { AAGATAGAAACCAACCTGGCTCAC }\end{array}$ & 53 & 126 \\
\hline Carboxypeptidase 4 & $\begin{array}{l}419 \mathrm{~F} \\
419 \mathrm{R}\end{array}$ & $\begin{array}{l}\text { ATGGCAACCGCAACTACGACTTC } \\
\text { GGTCTCGATTTCGGAGAAGGCTG }\end{array}$ & 50 & 104 \\
\hline $\begin{array}{l}\text { Single domain major } \\
\text { allergen } 2\end{array}$ & $\begin{array}{l}59 \mathrm{~F} \\
59 \mathrm{R}\end{array}$ & $\begin{array}{l}\text { CTGGAGTTCGAAGAGTTCACGC } \\
\text { AGTAGTGGATGTCAATGCTGTGGC }\end{array}$ & 50 & 142 \\
\hline $\begin{array}{l}\text { Glutathione-s- } \\
\text { transferase } \\
\text { Actin }\end{array}$ & $\begin{array}{l}121 \mathrm{~F} \\
121 \mathrm{R} \\
105-2 \mathrm{~F} \\
105-2 \mathrm{R}\end{array}$ & $\begin{array}{l}\text { CGTACTTCAACATCACTGCTCTGG } \\
\text { GCCGTCAATTTCCAACACTGGTAC } \\
\text { GGTCAAGTCATCACAATCGGAAAC } \\
\text { CAGTGTTGGCGTACAAGTCCTTAC }\end{array}$ & $\begin{array}{c}50 \\
50-53\end{array}$ & $\begin{array}{l}155 \\
160\end{array}$ \\
\hline
\end{tabular}


Table 2. Sequences identified from gut libraries of $D$. noxia RWA2 and RWA1

with similarity to proteases and protease inhibitors from other insects.

\begin{tabular}{|c|c|c|c|c|}
\hline \multicolumn{5}{|c|}{$\begin{array}{l}\text { Number of } \\
\text { sequences }\end{array}$} \\
\hline Contig & $\frac{\text { Bio }}{2}$ & $\frac{e}{1}$ & Annotation & E-Value \\
\hline 18 & 26 & 0 & trypsin-like serine protease [Ostrinia nubilalis] & 0 \\
\hline 19 & 27 & 0 & trypsin-like serine protease [O. nubilalis] & 0 \\
\hline 20 & 16 & 0 & trypsin-like serine protease [ $O$. nubilalis] & $2.00 \mathrm{E}-178$ \\
\hline 21 & 1 & 0 & trypsin-like serine protease [ $O$. nubilalis] & $2.00 \mathrm{E}-119$ \\
\hline 67 & 10 & 0 & chymotrypsin-like serine protease [ $O$. nubilalis] & 0 \\
\hline 68 & 1 & 0 & chymotrypsin-like serine protease $[O$ O. nubilalis $]$ & 0 \\
\hline 87 & 8 & 0 & trypsin-like serine protease $[O$. nubilalis] & $1.00 \mathrm{E}-168$ \\
\hline 99 & 2 & 0 & trypsin-like serine protease 12 [O. nubilalis] & $1.00 \mathrm{E}-176$ \\
\hline 100 & 3 & 0 & trypsin-like serine protease 12 [O. nubilalis] & $1.00 \mathrm{E}-169$ \\
\hline 101 & 2 & 0 & trypsin-like serine protease 12 [O. nubilalis $]$ & $1.00 \mathrm{E}-176$ \\
\hline 469 & 0 & 2 & serine protease inhibitor 4 [Acyrthosiphon pisum] & $8.00 \mathrm{E}-78$ \\
\hline 747 & 1 & 0 & serine protease 24 [Mamestra configurata] & $3.00 \mathrm{E}-76$ \\
\hline 781 & 1 & 0 & chymotrypsin-like protease 16 [ $O$. nubilalis] & $5.00 \mathrm{E}-72$ \\
\hline 823 & 1 & 0 & chymotrypsin-like serine protease 6 [O. nubilalis] & $1.00 \mathrm{E}-177$ \\
\hline 839 & 1 & 0 & serine protease inhibitor $1 \mathrm{~b}$ [Choristoneura fumiferana] & $5.00 \mathrm{E}-89$ \\
\hline 88 & 2 & 2 & serine proteinase diverged [ $O$. nubilalis] & $1.00 \mathrm{E}-150$ \\
\hline 89 & 0 & 0 & serine proteinase diverged $[O$. nubilalis $]$ & $1.00 \mathrm{E}-142$ \\
\hline 90 & 1 & 0 & serine proteinase diverged [O. nubilalis] & $1.00 \mathrm{E}-150$ \\
\hline 91 & 1 & 0 & serine proteinase diverged [O. nubilalis] & $1.00 \mathrm{E}-126$ \\
\hline 92 & 1 & 1 & serine proteinase diverged [ $O$. nubilalis] & $4.00 \mathrm{E}-62$ \\
\hline 93 & 6 & 0 & trypsin-like serine proteinase $\mathrm{T} 21$ [O. nubilalis] & $1.00 \mathrm{E}-166$ \\
\hline 94 & 1 & 0 & trypsin-like serine proteinase $\mathrm{T} 21[\mathrm{O}$. nubilalis $]$ & $1.00 \mathrm{E}-161$ \\
\hline 95 & 1 & 0 & trypsin-like serine proteinase $\mathrm{T} 21$ [O. nubilalis] & $1.00 \mathrm{E}-163$ \\
\hline 449 & 2 & 0 & putative chymotrypsin 4 [ O. nubilalis] & 0 \\
\hline 511 & 0 & 2 & kazal-type proteinase inhibitor [A. pisum] & $1.00 \mathrm{E}-54$ \\
\hline 815 & 1 & 0 & putative chymotrypsin 17, partial [ $O$. nubilalis] & $1.00 \mathrm{E}-157$ \\
\hline 845 & 1 & 0 & chymotrypsin-like proteinase $\mathrm{C} 3$ [O. nubilalis] & 0 \\
\hline 849 & 1 & 0 & putative chymotrypsin 8 [O. nubilalis] & $2.00 \mathrm{E}-12$ \\
\hline 856 & 1 & 0 & putative chymotrypsin 10 [O. nubilalis] & $7.00 \mathrm{E}-58$ \\
\hline 888 & 1 & 0 & putative chymotrypsin 8 [O. nubilalis] & 0 \\
\hline 994 & 0 & 1 & metalloproteinase $[$ A. pisum] & 0 \\
\hline
\end{tabular}




\section{Figure 1A}

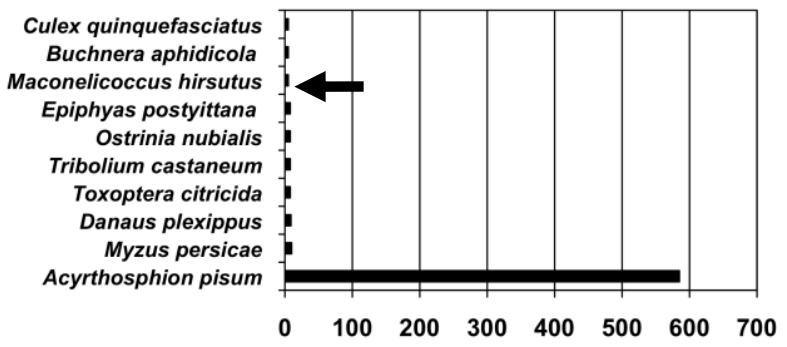

Number of sequences
Figure 1B

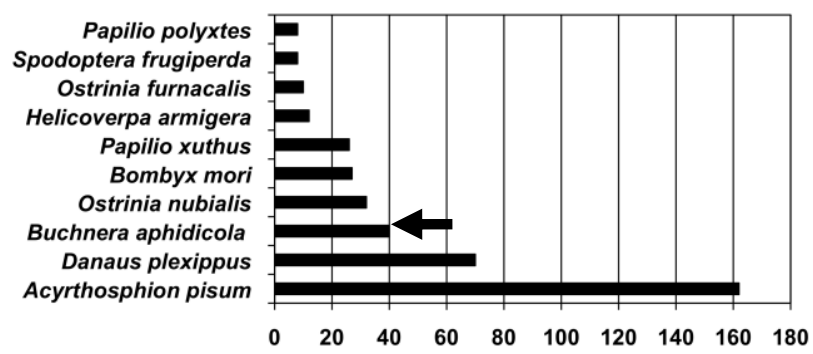

Number of sequences

Fig. 1. Ten species with greatest similarity to sequences (contigs/singlets) in $D$. noxia biotype 1 (RWA1, green bars) and biotype 2 (RWA2, brown bars) gut libraries after BLAST analysis.

Arrows show the difference in the numbers of Buchera aphidicola sequences in both libraries. 
Fig. 2. Numbers of contigs/singlets present in $D$. noxia biotype 1 (RWA1, green bars) and biotype 2 (RWA2, brown bars) gut libraries categorized by Molecular Function GO.

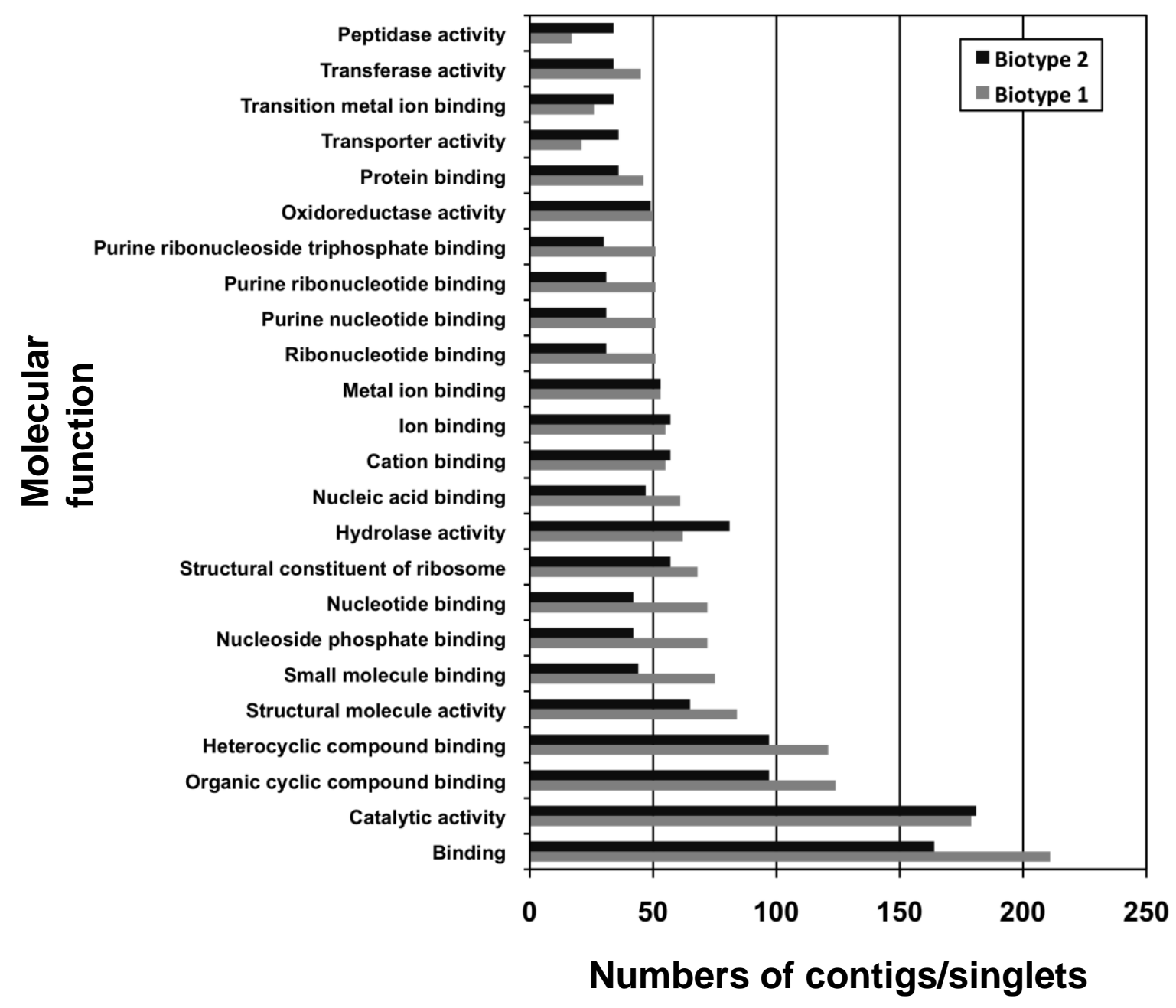


Fig. 3. Percentage of D. noxia gut transcripts mapped to metabolic pathways using the KEGG server in biotype 1 (RWA1, green bars) and biotype 2 (RWA2, brown bars).

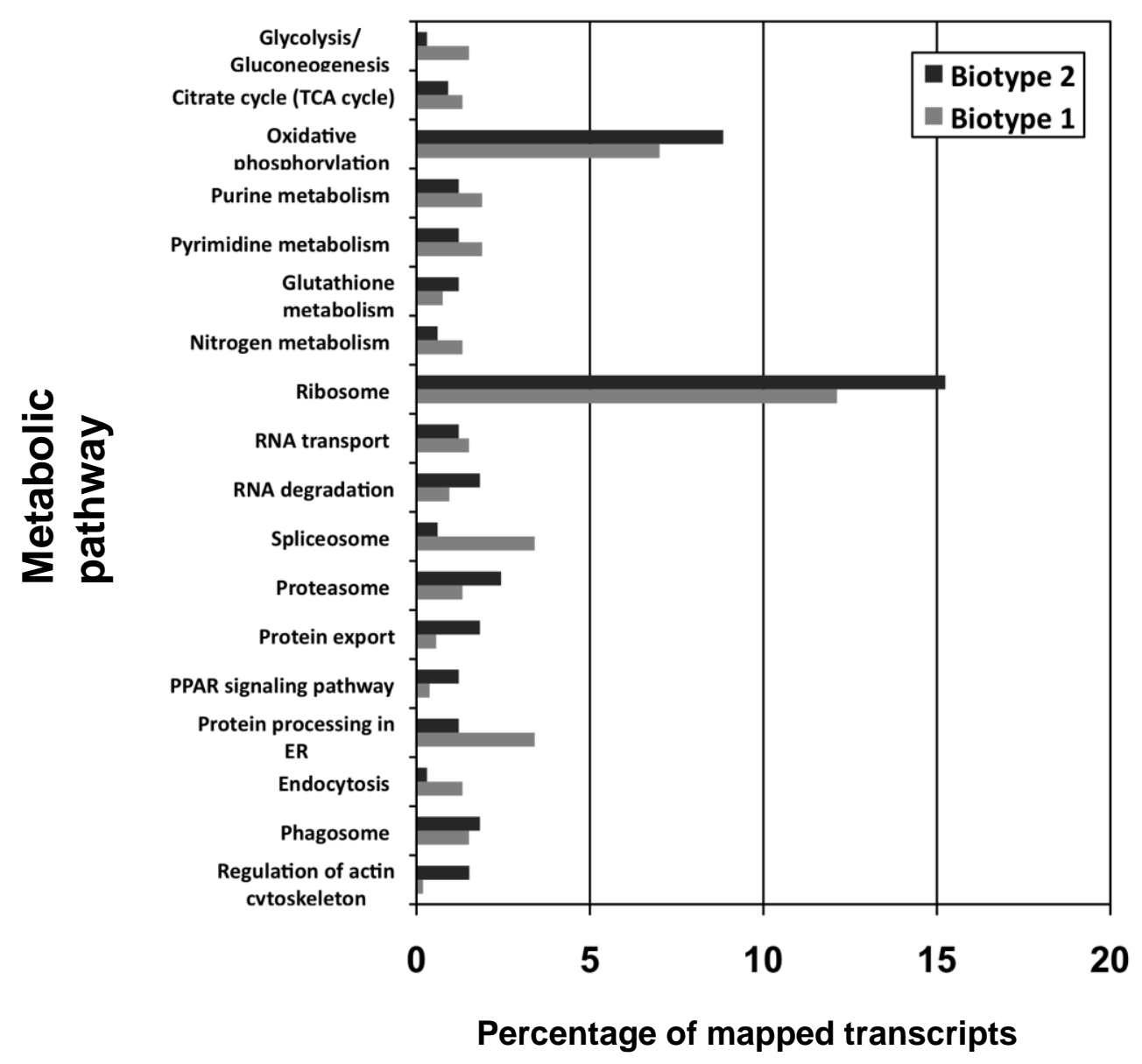


Figure 4

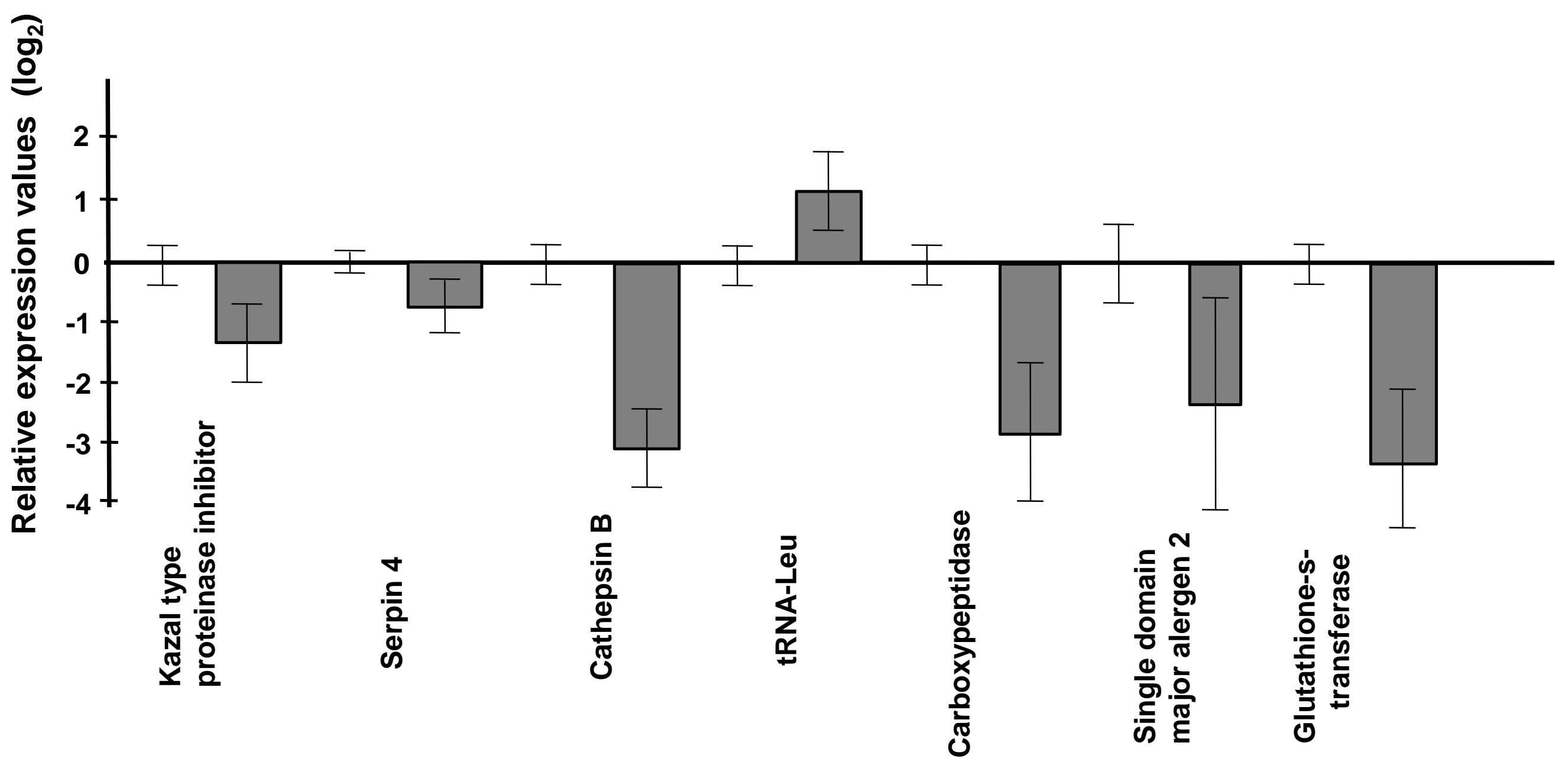

Fig. 4. Relative expression (Mean \pm SD) of seven genes in gut tissues of $D$. noxia biotype 1 and 2 (RWA1 and RWA2). Relative expression values $\left(\log _{2}\right)$ of transcripts in RWA2 in comparison to RWA1 feeding on wheat carrying Dn4 resistance gene. Shaded bars represent expression profiles of respective transcripts in RWA2. 